\title{
Asbestos: mining exposure, health effects and policy implications
}

\author{
Kristina Luus *
}

\begin{abstract}
The purpose of this paper is to review research in the health effects and risks associated with exposure to asbestos and then to use this scientific evidence to analyze the implications of Canada's current policy on the use, manufacturing and export of asbestos. The review begins with a brief historical introduction to asbestos, and then moves on to look at the risks associated with asbestos exposure. Epidemiological and in vitro studies are then analyzed to determine the health risks of asbestos, with a specific focus on the different effects of serpentine and amphibole asbestos fibres. The paper then concludes with an analysis of Canadian policy in light of established scientific evidence and with a discussion of the possible implications of a gap between scientific knowledge and public policy.
\end{abstract}

\section{INTRODUCTION}

This critical examination of the historical and current health effects of exposure to asbestos will first focus on a historical introduction to asbestos, and then assess the risks of exposure, causes of health problems and resulting health effects of exposure to asbestos. Focus is placed on assessing occupational health risks associated with mining asbestos, with special emphasis on differentiating between the health risks of different types and lengths of asbestos fibres. The purpose of this focus is to assess the validity of claims made by policymakers and the Chrysotile Institute that the type of asbestos mined in Canada is significantly safer than other types of asbestos $(1,2)$. The review of scientific literature will then be used to inform a policy critique of Canada's asbestos policies.

\footnotetext{
Asbestos

Asbestos are fibrous, naturally occurring hydrated silicates that have long been mined and used for their fire-retardant and insulating properties as construction materials $(3,4)$. Asbestos can be found in amphibole and serpentine forms $(5,6)$. 95\% of the asbestos mined globally is in a serpentine form of chrysotile type, with

*To whom correspondence should be addressed: Kristina Luus 1173 Wellington Street Apt. 33, Halifax, NS B3H 3A2

Email: kluus@dal.ca
}

fibres that are long and curly (7). Amphibole forms of asbestos may be of amosite, crocidolite or anthophyllite types, and are shorter and straighter than serpentine varieties. According to the Stanton Hypothesis, amphibole fibres were originally believed to pose less risk $(4,6)$, but these fibres were then linked to increased rates of mesothelioma (8).

\section{History of exposure}

Dr. Montague Murray first recognized the negative health effects of asbestos in 1899 (9). However, dust control legislation for mines was not enacted in North America until 1971 (3). In the intermediate years, mining and use of asbestos increased dramatically by 120 -fold, peaking upon the enaction of legislation in 1971, and decreasing exponentially until the present (Figure 1). The current decreases in the rate of mining are due to public health concerns and to the progressively more restrictive standards placed upon the level of asbestos dust allowed in mines, from 5 fibres $/ \mathrm{cm}^{3}$ in 1971 (3) to 1 fibres $/ \mathrm{cm}^{3}$ at present (10). Although the global levels of asbestos mined have decreased significantly, Canada continues to be one of the world's leading producers. $2.4 \times 10^{5}$ tonnes were mined in Canada in 2003 (11), which accounted for much of the world's production of asbestos (12). 


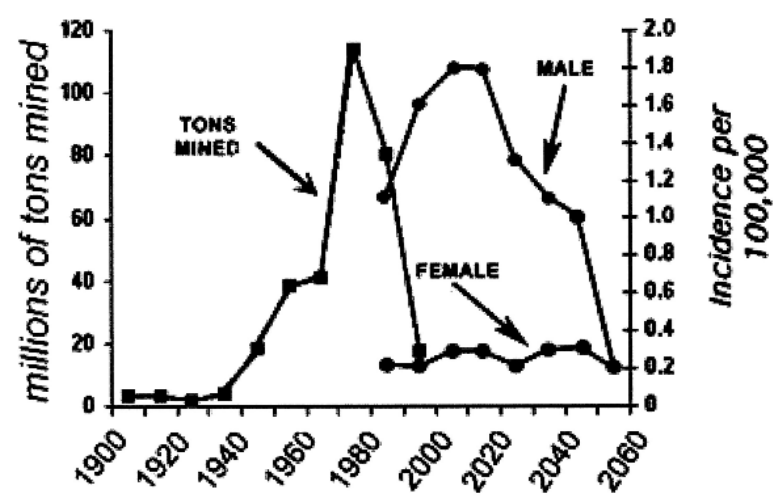

Figure 1. Correlation of Asbestosis and Asbestos Mined from 19002055 in the United States (Cudgell and Kamp, 2004)

\section{Current risks}

Adverse health effects from exposure to asbestos remain a serious concern to miners, mining communities and residents of buildings that contain asbestos. Miners and mining communities are at the greatest risk from asbestos related diseases, but are better prepared to limit their exposure to asbestos than homeowners who are unknowingly breathing in asbestos. There is a time lag of 15 to 40 years between exposure and asbestos-caused disease for both residents and miners, which often makes it difficult to relate historical exposure to current symptoms (Figure 2) (7, $3)$. Asbestos has far-reaching and long-lasting impacts for human health, both through occupational and environmental exposure.

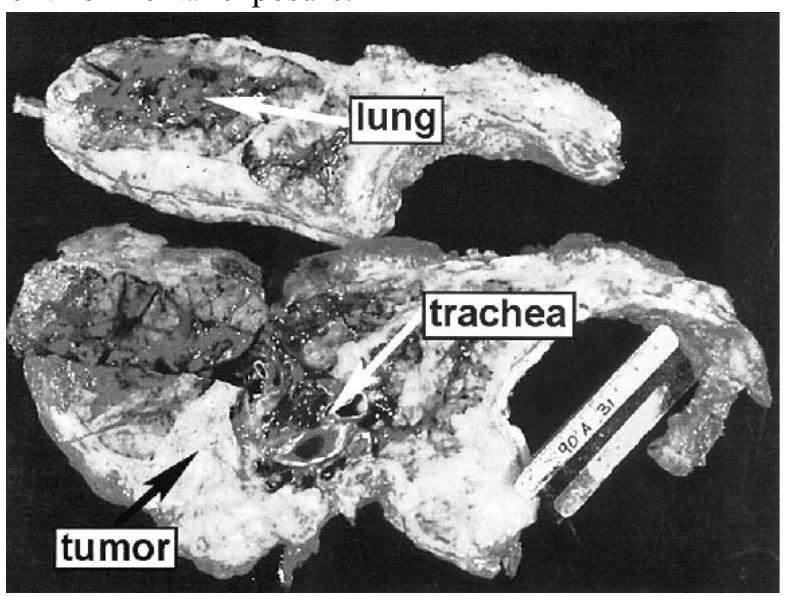

Figure 2. Malignant mesothelioma most frequently affects the lining of the lungs (3).

\section{EXPOSURE}

\section{Pathways}

Exposure to asbestos fibres occurs through ingestion, skin contact or inhalation $(3,9,13)$. Inhalation of asbestos fibres is dangerous and results in asbestosrelated diseases. Skin contact with raw asbestos fibres results in relatively harmless epidermal overgrowth. Ingestion of water from asbestos-contaminated pipes has not been found to increase the incidence of asbestos-related diseases (14). The remainder of this essay will therefore focus exclusively on inhalation of asbestos fibres.

\section{Persistence}

Asbestos occurs naturally underground in trace quantities. Amphiboles are naturally present in surface soils in specific regions of several countries including Finland, Greece and Afghanistan, and affect local residents (3). However, since asbestos is only dangerous when inhaled, subsurface deposits pose little risk. When these deposits are mined, airborne concentrations increase greatly In Libby, Montana, mining and processing of asbestos-contaminated talc and vermiculite increased airborne asbestos concentrations from $<0.004$ in 1847 to 0.022 fibres $/ \mathrm{cm}^{3}$ in 1995 . These airborne concentrations become embedded in the tree bark, where the asbestos persists and can affect those who harvest the contaminated wood (15). Exposure to asbestos can occur when workers process products such as talc and vermiculite that are naturally contaminated by tremolite (3). Asbestos-contaminated vermiculite was mined in Libby, Montana for 70 years, leading to infection of both workers and the community since workers brought home materials from the mine and used them as clean fill in constructing driveways and gardens. Asbestos therefore persists in trace amounts in soil and in larger concentrations in buried waste sites (16).

\section{Risk}

The risks associated with asbestos are significant, and workers have historically been subjected to concentrations 10-100 times the Canadian legal limit of 1 fibres $/ \mathrm{cm}^{3}(3,17,13)$. These workers have suffered from a wide range of health effects. Asbestos has a significant risk even at lower concentrations. The families of workers have therefore had elevated rates of asbestos-related diseases from the asbestos inadvertently brought home on the clothing of miners. Radiographs of the spouses of workers exposed to asbestos indicated that $19 \%$ of them suffered from pleural changes, and that the only factor of significance in detailed questionnaires was the latent period since first exposure. The microscopic fibres of asbestos are therefore impossible to eliminate from the indoor air environment, and pose a significant risk for the workers, their families and those whose homes contain airborne asbestos. 


\section{CAUSES OF HEALTH PROBLEMS}

Exposure to asbestos results in a variety of health problems caused by the autoimmune, genotoxic and irritative effects of asbestos. Within each of these categories, case studies and experiments will be referred to in order to illuminate differences between the mechanisms of different types of asbestos.

\section{Autoimmunity}

Autoimmune diseases such as rheumatoid arthritis, systemic lupus erythematosus and multiple sclerosis have been found at increased rates in populations exposed to asbestos (13). An epidemiological study of the autoimmune effects of asbestos exposure was conducted on 7,307 residents of Libby, Montana who had undergone occupational and environmental exposure to amphibole asbestos from a local vermiculite mine $(18,13)$. Of these residents, $6.7 \%$ were diagnosed with auto-immune diseases, compared to a rate of $1 \%$ in an unexposed population in Missoula, MT. Furthermore, elevated levels of autoantibodies were detected in the exposed population at a rate $28.6 \%$ higher than the general Missoula population. However, despite the statistical significance of these findings, the causation between asbestos exposure and autoimmune diseases is still incompletely explored. Asbestos is believed to bring about systemic autoimmunity by suppressing the body's natural killer cells, and has been thought to increase the incidence of lung cancer by suppressing pulmonary parenchymal cells $(19,21)$. A study exposed mice to serpentine chrysolite asbestos and amphibole crocidolite asbestos to compare the effects of these two types of asbestos on autoimmunity.

The results from this experiment determined that crocidolite asbestos had a slightly more toxic impact than chrysotile on the immune function of pulmonary parenchymal cells (20). This finding confirms the more damaging health effects overall of amphibole asbestos in comparison to serpentine asbestos.

\section{Genotoxicity}

The genotoxic effects of asbestos have been found both in factory workers (17) and their wives (21). In these studies, asbestos has been found to damage DNA, gene transcription and protein expression $(17,21)$. The resulting genotoxic effects would lead to inflammation, cell death and errors in modulating cell proliferation (7). Although further research is still required to identify the mechanisms through which asbestos incites genotoxicity, multilocus deletions of DNA in hybridhuman cells have been induced through exposure to crocidolite (22). Research on in vivo rats has found that chrysotile promotes genotoxicity more rapidly than crocidolite (23). This difference may be due to fibre length, as indicated by an in vivo experiment by Keane et al which found that the magnitude of asbestos-related disease on Chinese hamster lungs grew with the length of the fibre (24). Genotoxicity is therefore related to length, which means that longer serpentine chrysotile fibres are more genotoxic than short amphibole asbestos fibres. This finding runs counter to reviews that have summarized the effects of amphibole asbestos as more damaging that the effects of serpentine asbestos $(4,6)$. It is possible that the genotoxic effects are either less important or take longer to manifest than the health effects of irritation and autoimmunity, and therefore have not yet appeared in research literature because earlier studies included all forms of asbestos together (25).

\section{Irritation}

Upon inhalation, asbestos causes significant irritation to the lungs and bronchioles. The resulting irritation causes the lungs to try to digest the asbestos. However, because of its chemical and physical stability, the asbestos cannot be digested and instead becomes encased in scar tissue. Growing masses of scar tissue result in benign fibrosis, effusions and plaques in the lung cavity (12). Since crysolite fibres are thin-walled sheets of silicates, they have a half-life of of 0.3-11 days, whereas the double-chained chemistry of amphibole fibres have a much longer half life that extends from 500 days to infinity (25). It is therefore clear that amphibole fibres have a much more irritative effect on the lungs than crysolite fibres and are therefore much more likely to lead to asbestosis, effusions and plaques through irritation.

\section{RESULTING HEALTH EFFECTS}

The diseases that result from the aforementioned causes will now be analyzed, starting with the benign effects of asbestosis, effusions and plaques, and then moving on to bronchogenic lung cancer and malignant mesothelioma. After describing the symptoms and causes of each diseases, the incidence of each disease will then be analyzed in terms of the type of asbestos that the population was exposed to, to determine the varying risks of various types of asbestos.

\footnotetext{
Asbestosis

Asbestosis is a disease characterized by bilateral interstitial pulmonary fibrosis due to the inhalation of asbestos fibres $(26,3)$. The fibrosis of the lungs causes shortness of breath and dry cough. In severe cases, patients have difficulty with oxygen diffusion, since the disease primarily affects the base of the lungs (26). Amphibole fibres have been strongly linked to asbestosis through a series of nine epidemiological
} 
studies reviewed by Hessel et al (27). However, chrysotile fibres break apart so quickly that they result in no fibrosis at subchronic levels (3413 total fibres $/ \mathrm{cm}^{3}$ ) (25). Asbestosis is therefore contracted primarily through amphibole fibres.

\section{Plaques}

Pleural plaques occur when fibrosis is localized in a specific region of the lung. Plaques are a distinctive feature of asbestos exposure that cause functional impairment $(28,3)$. However, whereas Goldsmith found plaques to be benign (28), Sprince et al have linked the presence of plaques with the emergence of cancer and immune deficiency (5). It seems likely that disagreements over the prognosis of plaques in terms of their propensity towards malignancy may be better resolved with a more thorough look at the differences in the rates of malignancy caused by the two main forms of asbestos. With this in mind, we will now turn to examine the two carcinogenic diseases caused by asbestos.

\section{Malignant mesothelioma}

Malignant mesothelioma is a type of cancer caused by asbestos that occurs in the lining of the lungs or the abdomen (Figure 2) (3). In a mortality study of Prieska, a South African town that had been milled and mined extensively for asbestos, it was found that the risk of death by malignant mesothelioma was $277 / 10^{6}$ (29). The current incidence of malignant mesothelioma is projected to double in Europe over the next 20 years due to increased knowledge about this disease, which is often missed or misdiagnosed as pneumonia (30). Rates of malignant mesothelioma are much greater when populations have undergone exposure to amphibole fibres, because of the greater persistence of amphibole fibres, and their greater autoimmune effect (31). McDonald et al. (32) have shown through an epidemiological study of asbestos workers in Quebec that the diminished rates of malignant mesothelioma associated with serpentine asbestos were also due to the lower concentrations of fibrous tremolite, an asbestos mineral with significant pathology.

\section{Bronchogenic lung cancer}

Bronchogenic lung cancer is brought about through interstitial pulmonary fibrosis, which then becomes malignant when the body's autoimmune defenses break down (3). An epidemiological study of a town in Turkey with natural deposits of asbestiform minerals found elevated rates of bronchogenic lung cancer. Upon autopsy of a patient who died from lung cancer, many asbestos bodies were found. They were composed of tremolite fibres with few chrysolite fibres (33). This finding supports the evidence mentioned in the previous section that amphibole asbestos is more irritative and persistent in the lungs and has a stronger autoimmune effect. It also supports the findings that tremolite concentrations increase the incidence of cancer (32). The increased irritation causes the fibrosis that results in tumors. The breakdown of the autoimmunity in the lungs then results in bronchogenic lung cancer.

\section{Effusions}

Effusions occur when fluids accumulate in the lungs. These events can be acute with complete resolution, or can be chronic and result in significant accumulations of fluid with associated fever and pain (3). If severe, effusions can result in rounded ateclatasis, where the lung is left without air. Effusions occur frequently when mesothelioma sets in, but can also result from benign fibrosis, plaques and nonspecific fibrous thickening (34). Effusions are therefore symptoms of asbestos exposure that can result in death. Amphibole fibres have been associated with effusions more so than chrysolite fibres (34), likely because amphibole fibres are more irritative and long-lasting in the lungs (25).

\section{CANADIAN POLICIES ON ASBESTOS}

Despite the increased knowledge of the risks and consequences of exposure to asbestos, Canadians continue to be exposed to asbestos through unintended environmental exposure, and occupational exposure at levels of up to 1 fibre $/ \mathrm{cm}^{3}$. It is therefore vital that this analysis of the health effects of asbestos conclude with an analysis of current legislation for asbestos and its implications in light of scientific evidence, as well as a list of policy recommendations.

\section{Current Legislation}

The Canadian Government currently prohibits the spraying of mixtures of fibres that contain asbestos if the fibres are not fully encapsulated during spraying in Item 40 in Part 1 of Schedule 1 to the Hazardous Products Act (HPA) (35). Products containing crocidolite asbestos fibres are banned, but an exemption in 12(f) of the HPA states that these products are not banned if they are "packaged as a consumer product" (35). Finally, Item 37 in Part 1 of Schedule 1 of the HPA bans the advertising, sale and importing of all products that consist in their entirety of asbestos fibre. The background to this section of the HPA reads:

\footnotetext{
the addition of this item to the Schedule does not affect the commerce of products that contain asbestos as an ingredient (irrespective of the concentration of asbestos) nor the sale/importation of pure asbestos to/by industrial users (35)
} The ban is therefore so narrow as to have little effect on community-level exposure to asbestos. 
Canada also continues to export chrysotile to the EU despite their ban under the justification that "Canada considers that the bans imposed by many EU Member States and the Commission cannot be justified by scientific risk assessments" (36). Meanwhile, a wealth of scientific evidence referred to previously in this review has demonstrated that evidence directly links chrysotile asbestos with health risks.

Workers who process chrysotile or have been exposed to asbestos for over 2,000 hours in their lifetime must undergo a mandatory chest x-ray (37). However, the implications of this regulation regarding compensation and health care are unclear when a problem is detected.

\section{Implications}

The laxness of the regulations concerning the sale, export and mining of asbestos has detrimental consequences for the health of Canadian communities. The Chrysotile Institute continues to receive federal subsidies to mine asbestos in Quebec, and sets safety regulations "in accordance with government" in Canada (1). The safety regulations developed were described in the previous section, and since these regulations protect corporate interests more than community health, there are serious implications for community health.

Since asbestos-related diseases appear many years after first exposure to asbestos (Figure 3), it is often difficult to establish a link between disease and exposure, especially since smoking and genetics are confounding factors in the incidence of asbestos-related diseases. Lawyers and corporations have therefore depended on scientists to prove or disprove this link. Miller (2006) found in his analysis of radiographic readings for asbestosis using International Labour Office classification that evidence has been misused by the media and attorneys to give undue compensation to victims. However, evidence has also been found that victims of asbestos exposure are often misdiagnosed, and fail to receive adequate protection (4). The lack of firm government guidelines for the use and mining of asbestos is therefore of great detriment to miners and their communities.

\section{Recommendations}

Since epidemiological analyses and animal testing have clearly shown that asbestos has health effects through occupational and environmental exposure, it is the responsibility of the government to protect the health of its citizens instead of yielding to economic corporate interests. The government of Canada must stop exporting asbestos to EU countries in which asbestos has been banned, instead of continuing to challenge the rights of these countries to refuse imports using WTO guidelines (36). Although chrysotile is less potent than other forms of asbestos, serious questions must be asked about whether the benefits of economic development in Quebec outweigh the long-term health consequences of exposure to asbestos. One potential way in which these costs and benefits can be better balanced is by forcing companies such as the Chrysotile Institute to assume responsibility for the compensation of people affected by asbestos.

Overall, better monitoring is required, both of the health of miners and their communities and of indoor air

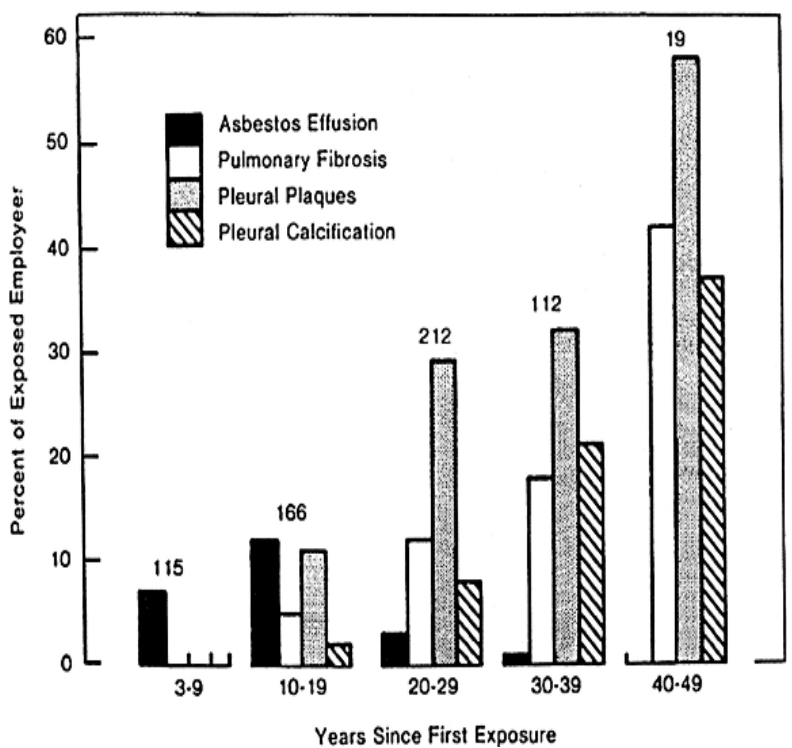

Figure 3. Delay between the time of first exposure and employee diagnosis with asbestos-related diseases (Kamp and Weitzman, 1999)

quality in buildings containing asbestos. Despite claims that indoor air quality testing of public buildings is unnecessary and unduly frightens the population, the overwhelming risks of exposure and subsequent health effects warrant testing these sites for indoor air quality. It is only through a thorough knowledge of the potential health effects of a specific site that informed policies can be created.

The purpose of this paper has been to review current scientific literature on the risks and health effects of exposure to different types of asbestos, and then use this scientific evidence to critically analyze current Canadian policies. The main problem in the existing policies is that they are not based on scientific evidence of the health effects of asbestos, and are designed not to mitigate these effects, but to create an appearance of maintaining public health standards while yielding to corporate interests. The continuing health consequences of asbestos are therefore a prime example of the way in which policymakers are choosing short-term economic benefits instead of minimizing scientifically established risks, to the great detriment of our communities. 


\section{REFERENCES}

1. Chrysotile Institute. About the Institute. http://www.chrysotile.com/en/about.aspx. 2006.

2. Health Canda. Inventory of Federal, Provincial and Territorial Environmental and Occupational Health Data Sources and Surveillance Activities. http://www.hc-sc.gc.ca/ewhsemt/pubs/eval/inventory-repertoire/asbestON_e.html. 2003.

3. Cudgell, D. W. and D. W. Kamp. Asbestos and Pleura. Chest 2004; 125: 1103-1117.

4. Mossman, B.T., J. Bignon, M. Corn, A. Seaton and J.B.L. Gee. Asbestos: Scientific Developments and Implications for Public Policy. Science 1990; 247: 294-301.

5. Sprince, N. L., L.C. Oliver, TC McLoud et al. Asbestos exposure and asbestos-related pleural and parenchymal disease: associations with immune imbalance. American Review of Respiratory Disorders 1991; 142: 843-847.

6. Churg, A. Deposition and Clearance of Chrysotile Asbestos. British Occupational Hygiene Society 1994; 38(4): 625-633.

7. Kamp, D.W. and S.A. Weitzman. The Molecular Basis of Asbestos Induced Lung Injury. Thorax 1999; 54: 638-652.

8. Suzuki Y, Yuen SR, Ashley R. Short. Thin asbestos fibers contribute to the development of human malignant mesothelioma: pathological evidence. International Journal of Hygiene and Environmental Health 2005; 208(3): 201-10.

9. Tweedale, G. and P. Hansen. Protecting the Workers: the Medical Board and the Asbestos Industry, 1930s-1960s. Medical History $1998 ; 42:$ 439-457.

10. Health Canada. Health Effects of Chrysotile and other Asbestos Fibres in Support of the Consultation Document on the Addition of Chrysotile Asbestos to the PIC Procedure of the Rotterdam Convention. www.ec.gc.ca/nopp/docs/consult/Rotterdam/ca/ pdf/chrysotileHealth-BG_E.pdf. 2004.

11. Freedman, B. Environmental Science. A Canadian Perspective, 4 ed. Toronto: Pearson Prentice Hall; 2007.

12. Pedley, F. G. Asbestosis. Canadian Medical Association Journal, 253-254. 2005.

13. Renner, Rebecca. Asbestos and Autoimmunity: More Bad News from Libby? Environmental Health Perspectives 2005; 113(1): 51.

14. Polissar, L., R.K. Severson and E.S. Boatman. A Case-Control Study of Asbestos in Drinking Water and Cancer Risk. Journal of Epidemology 1984; 119(3):456-471.

15. Webber J.S., M. Getman and T.J. Ward. Evidence and Reconstruction of Airborne Asbestos from Unconventional Environmental Samples. Inhalation Toxicology 2006; 18(12): 969-973.

16. Anderson, B.A., S.M. Dearwent, J.T. Durant, J.J. Dyken, J.A. Freed, S.M. Moore and J.S. Wheeler. Exposure Pathway Evaluations for Sites that Processed Asbestos-Contaminated Vermiculite. International Journal of Hygiene and Environmental Health 2005; 208(1-2): 55-65.

17. Berry, G., M.L. Newhouse and J.C. Wagner. Mortality from all Cancers of Asbestos Factory Workers in East London 19331980. Occupational Environmental Medicine 2000; 57: 782785

18. Pfau JC, Sentissi JJ, Weller G, Putnam EA. Assessment of autoimmune responses associated with asbestos exposure in Libby, Montana, USA. Environmental Health Perspectives 2005; 113(1):25-30.

19. Tsang PH, Chu FN, Fischbein A, Bekesi JG. Impairments in functional subsets of T-suppressor (CD8) lymphocytes, monocytes, and natural killer cells among asbestos-exposed workers. Clin Immunol Immunopathol 1988; 47(3):323-332.

20. Rosenthal, G. J., E. Corsini and P. Simeonova. Selected New
Developments in Asbestos Immunotoxicity. Environmental Health Perspectives Supplements 1998; 106(1): 159-169.

21. Sider, L., E.A. Holland, T.J. Davis and D.W. Cudgell. Changes on Radiographs of Wives of Workers Exposed to Asbestos. Radiological Society of North America 1987; 164: 723-726.

22. Xu, A., H. Zhou, D.Z. Yu and T.K. Hei. Mechanisms of the Genotoxicity of Crocidolite Asbestos in Mammalian Cells: Implications from Mutation Patterns Induced by Reactive Oxygen Species. Environmental Health Perspectives 2002; 110(10): 1003-1008.

23. Michiels, F.M., G. Moens, J.J. Montagne and I. Chouroulinkov. Biological Effects of Asbestos Fibres on Rat Lung Maintained in Vitro. Institute of Applied Research in Cancer 1989; 90: 156160.

24. Keane, M.J., J.W. Stephens, B.Z. Zhong, W.E. Miller, T.M. Ong and W.E. Wallace. A Study of the Effect of Chrysotile Fibre Surface Composition on Genotoxicity in Vitro. Journal of Toxicology and Environmental Health 1999; 57(8): 529-541.

25. Bernstein, D.M. and J.A. Hoskins. The Health Effects of Chrysotile: Current Perspectives Based upon Recent Data. Regulatory Toxicology and Pharmacology 2006; 45(3): 252264.

26. Mossman, B.T. and A. Churg. Mechanisms in the Pathogenesis of Asbestosis and Silicosis. American Journal of Respiratory Critical Care Medicine 1998; 157(5): 1666-1680.

27. Hessel, P.A., J.F. Gamble and J.C. McDonald. Asbestos, Asbestosis, and Lung Cancer: a Critical Assessment of the Epidemiological Evidence. Thorax 2005; 60: 433-436.

28. Goldsmith, J.R. Asbestos as a systematic carcinogen: the evidence from eleven cohorts. American Journal of Clinical Pathology 1982; 80: 14-20.

29. Kielkowski, D., G. Nelson and D. Rees. Risk of Mesothelioma from Exposure to Crocidolite Asbestos: a 1995 Update of a South African Mortality Study. Occupational Environmental Medicine 2000; 57: 563-567.

30. Peto, J., A. Decarli, C. La Vecchia, F. Levi, E. Negri. The European Mesothelioma Epidemic. British Journal of Cancer 1999; 79(3-4): 666-672.

31. McDonald, J.C. and A.D. McDonald. The Epidemiology of Mesothelioma in Historical Context. European Respiratory Journal 1996; 9: 1932-1942.

32. McDonald, J.C., A.D. McDonald and J.M. Hughes. Chrysolite, Tremolite and Carcinogenicity. Annals of Occupational Hygiene 1997; 41(6): 699-705.

33. Yazicioglu, S., R. Ilcayto, K. Balci, B.S.Sayli and B. Yorulmaz. Pleural Calcification, Pleural Mesotheliomas, and Bronchial Cancers Caused by Tremolite Dust. Thorax 1980; 35: 564-569.

34. Davies, D., M.I. Andrews and J.S. Jones. Asbestos Induced Pericardial Effusion and Constrictive Pericarditis. Thorax 1991; 46: 429-432.

35. Health Canada. Hazardous Materials Information System: Substance-Specific Issues. http://www.dfait-maeci.gc.ca/tnanac/2001/5-en.asp?format=print. 2006.

36. Government of Canada. Opening Doors to the World: Canada's International Market Access Priorities 2001. http://www.dfaitmaeci.gc.ca/tna-nac/2001/5-en.asp?format=print. 2001

37. Health Canda. Inventory of Federal, Provincial and Territorial Environmental and Occupational Health Data Sources and Surveillance Activities. http://www.hc-sc.gc.ca/ewhsemt/pubs/eval/inventory-repertoire/asbestON_e.html. 2003.

38. Miller, A. Radiographic Readings for Asbestosis: Misuse of Science-Validation of the ILO Classification. American Journal for Industrial Medicine 2006; 50(1): 63-67. 